\title{
Evaluation of nutritional status of foreign students at King Saud University, Kingdom of Saudi Arabia
}

\author{
Mohammed A Mohammed, Ghedeir M Alshammari* and Elfadil E Babiker* ${ }^{*}$ \\ Food Science and Nutrition Department, College of Food and Agricultural Sciences, King Saud University, P. O. Box \\ 2460, Riyadh 11451, Kingdom of Saudi Arabia
}

Submitted 26 March 2020: Final revision received 23 June 2020: Accepted 13 July 2020: First published online 26 August 2020

\begin{abstract}
Objective: The current study was conducted to assess the nutritional status and associated risk factors among foreign students residing at King Saud University for different periods and to explore its correlations.

Design: A cross-sectional study was conducted during the spring semester of 2018. A total of 400 male students aged 18-35 years had participated in the current study after signing a written consent form according to Helsinki Declaration.

Setting: A structural questionnaire was used to collect data on daily food intake and habits and socio-economic characteristics. Nutrients of food intake were assessed using the Esha programme and compared with that of dietary requirement intake (DRI). A body composition analyser was used to measure body fat (BF), visceral fat (VF) and BMI. Spearman correlation coefficients and simple regression analysis were performed to determine associations between variables.

Participants: Foreign students residing for different periods ( $<6$ months: 200 students and >6 months: 200 students) were used as subjects.

Results: The students who stayed $<6$ months consumed lower level of some nutrients than that of the DRI compared with those stayed $>6$ months. Overweight and obesity were more common among students who stayed $>6$ months with high values of $\mathrm{BF}$ and VF. Several risk factors were positively or negatively correlated with the students' nutrition proxies.

Conclusion: Most of the students who stayed $>6$ months are suffered from overweight. Some independent variables were found to be significantly correlated with the students' nutrition proxies either positively or negatively.
\end{abstract}

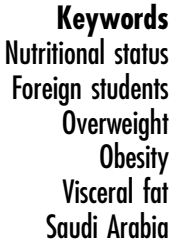

Keywords

Nutritional status reign students Overweight

Obesity Saudi Arabia
The number of post-graduate scholarships awarded at King Saud University has dramatically increased for international students, resulting in an increased number of international students attending the university. A study has been conducted on the dietary behaviours and cultures of immigrants and international students and concluded that the adjustment of foreign students to new cultures and the effect of nutrition risk factors on their dietary behaviour cannot be underestimated $^{(1)}$. Adverse changes in dietary patterns have been reported, including reduced intake of fruits and vegetables, increased intake of sweets and fats and increased energy level. Also, bad eating habits, such as meal skipping (especially breakfast), and an increase in snacking at irregular times have been reported ${ }^{(2)}$.

International students, unlike many other immigrants, are often physically separated from their parents and other relatives for the first time and are faced with many new experiences on their own. Therefore, appropriate dietary recommendations and education would be beneficial ${ }^{(3)}$. The prevalence of being overweight has increased and has become a major global health risk during the last few decades $^{(4)}$. Nutrition evaluation can detect abnormal changes in lifestyle before the problem develops into a more severe situation, causing adverse consequences ${ }^{(5)}$. Foreign students at King Saud University require attention because they are more susceptible to nutritional concerns like becoming overweight or malnourished. A study reported that university students have unsuitable dietary habits like skipping meals and consuming high amounts of high fat energy ${ }^{(6)}$.

The nutritional status of an individual is determined by body composition, health condition and functional status, as influenced by the utilisation of nutrients ${ }^{(7)}$. BMI is an important indicator to determine the central obesity 
prevalence in the overall population. However, it may over- or underestimate obesity, depending on certain circumstances $^{(8)}$. Also, Lee et al. ${ }^{(9)}$ stated that BMI has been used as an indicator of a patient's obesity, but it does not always reflect the degree of a patient's visceral fat (VF) properly due to the fact that the distribution of fat tissue varies between individuals. VF had high lipogenic and lipolytic activities. VF obesity, in which fat accumulation predominates in the intraabdominal cavity, is more frequently accompanied by disorders of glucose and lipid metabolism. It is also found among patients with hypertension rather than subcutaneous fat obesity ${ }^{(10)}$. The percentage of body fat (BF) accurately reflects body composition than BMI but both have been used for the assessment of human health problems like CVD in clinical practice ${ }^{(11,12)}$. A rise in the percentage of $\mathrm{BF}$ or $\mathrm{BMI}$ indicates higher levels of $\mathrm{CVD}^{(13)}$.

The rapid development of the Saudi Arabian economy during the last decades has brought about the adoption of a sedentary lifestyle and the consumption of a high-fat, lowfibre diet among adolescents ${ }^{(14)}$. Riyadh has experienced huge economic and population growth, especially in the final decades of the last century; it is the largest metropolitan area in Saudi Arabia and the Gulf states. Riyadh has social diversity and demographic and economic features that contribute to its unique character. Moreover, the city hosts the government's offices and all foreign diplomatic missions $^{(15)}$.

The evaluation of the nutritional status and daily food intake of foreign students staying in university boarding houses is important to identify their dietary habits and practices. This will help to improve their nutritional status through the recommendation of proper eating habits that are more compatible with their dietary needs, especially during the critical phases of developing their physical, sexual, mental and social characteristics. Therefore, the current study was conducted to evaluate the nutritional status of foreign students from different nationalities staying in King Saud University boarding houses for various periods of time and to explore related correlates.

\section{Research methods}

\section{Design and sampling method}

A cross-sectional study was carried out in King Saud University, Kingdom of Saudi Arabia, during the spring semester of 2018. A total of 400 under- and post-graduate male students with age ranging from 18 to 35 years were selected randomly from a sampling frame using a random numbers table according to a minimum sample size formula ${ }^{(16)}$ and after signing a form according to the Helsinki Declaration. All of the respondents are foreigners, including Middle Eastern (Yemen, Egypt, Algeria, Syria, Palestine, Jordan and Bahrain), Asian (Thailand,
Indonesia, Nepal, Bangladesh, China, Pakistan, India, Afghanistan and Uzbekistan), African (Sudan, Cote d'Ivoire, Niger, Nigeria, Tanzania, Somalia, Uganda, Mali, Burundi, Djibouti, Togo, Benin, Congo, Burkina Faso and Cameroon) and naturalised European (United Kingdom, Denmark and Holland) ethnicities and were randomly selected by college and class year using a stratified sampling method. All students came to Saudi Arabia from their home countries and directly enrolled in the university. The sample was divided into two groups: those who had been enrolled for $<6$ months (not fully adapted to the new environment and busy with the enrollment procedure for their first semester) and those who had been enrolled for more than 6 months (fully adapted to Saudi environment). Both groups attended the University from their home country and none of them resides in Saudi Arabia and then enrolled in the University.

\section{Data collection}

A structured interview guided by a questionnaire aimed at collecting a range of information (e.g., health data, socioeconomic data and dietary habits) was conducted by the researchers and two data collectors who were acquainted with the nature and goal of the study. Subjects were screened for inclusion via personal interviews.

The nutrients of the students' dietary consumption were recorded using the Esha programme. According to the Esha programme menu, a code was given to each type of food. In case of mixed and cooked food, contents provided separately. The 24-h recall food intake data (average of three measurements) for each student to the Esha food processor programme were entered. Thereafter, the software analyses the food and gives a percentage of all nutrients including energy content that has been taken by the respondents and then compares with the dietary requirement intake (DRI) reported by WHO/FAO dietary guidelines prepared for different populations.

\section{Anthropometric measurements}

Anthropometric measurements including BMI $\left(\mathrm{kg} / \mathrm{m}^{2}\right), \mathrm{BF}$ percentage (BF\%) and VF level were measured using a bioelectrical impedance analysis device (MC-780MA, TANITA Corp.). With fluctuations in the water content in the body that are expected to affect body composition, measurements were taken in the morning when students stayed without eating, drinking, showering or exercising for at least 2 h. Following the manufacturer's instructions, students were asked to wipe off the sole of their feet before stepping onto the measuring platform as unclean foot pads interfere with the device conductivity. BMI which is the ratio of weight in $\mathrm{kg}$ to height in $\mathrm{m}^{2(17)}$ was used to assess body weight status.

According to bioelectrical impedance analysis device instruction manual, adults were classified based on their BMI into underweight $(\mathrm{BMI}<18.5)$, normal 
$(\mathrm{BMI}=18 \cdot 5-24 \cdot 9)$, overweight $(\mathrm{BMI}=25-29 \cdot 9)$ or obese $(\mathrm{BMI} \geq 30)$. Furthermore, obesity was subdivided into three grades: Grade 1 (BMI = 30-34.9), Grade 2 (BMI = 35-39.9) and Grade 3 or extreme obesity (BMI $\geq 40$ ). According to Kyle et al. ${ }^{(18)}$ and taking into consideration age of respondents, the participants were classified as having low (BF\% $<11)$, normal $(\mathrm{BF} \%=11-21.9 \%)$, high $(\mathrm{BF} \%=22-27)$ or very high $(\mathrm{BF} \%>27) \mathrm{BF}$, and $\mathrm{VF}<10$ level = low, 10-14.9 level $=$ normal, $15-20$ level $=$ high, $>20$ level $=$ very high.

\section{Data analysis}

The statistical package for social sciences (SPSS Inc.) version 20 was used for the analysis of the data. The results were expressed as means. Student's $t$ test was used to find the correlation between student nutrients intake and dietary recommended intake. The statistical significance level is set at ${ }^{* *} P \leq 0.01 ; * P \leq 0.05$. The associations between socio-economic characteristics or food habits and nutritional proxies (BMI, BF and VF) were analysed through Spearman correlation coefficients. To estimate the relative contribution of socio-economic characteristics or food habits as independent variables to changing levels of nutritional proxies (BMI, BF and VF) as dependent variables we performed a simple regression analysis.

\section{Results}

The nutritional status of foreign students was evaluated according to the nutrients from their daily average food intake that obtained using the Esha programme to give the average nutrient consumption. Thereafter, the average intake of a nutrient was compared with the average values of the DRI using the Student $t$ test. Table 1 shows the average daily nutrient intake (24-h recall) in relation to the DRI for foreign students staying for different periods at King Saud University. The average energetic intake of students who stayed $<6$ months $(1970 \cdot 3 \mathrm{kcal})$ was lower than the DRI (2000 kcal); however, the difference is not significant. The average energetic intake of students who stayed $>6$ months $(9860.62 \mathrm{~kJ})$ significantly $(P \leq 0.01)$ exceeded that of the DRI. The amount of protein, carbohydrates and vitamins and minerals consumed by both groups was significantly $(P \leq 0.01)$ higher than that of the DRI. For both groups, the amount of dietary fibre consumed was significantly $(P \leq 0.01)$ lower than that of the DRI.

The total and saturated fats consumed by students who stayed $>6$ months were significantly $(P \leq 0 \cdot 01)$ higher than that of the DRI; however, this was lower than that of the DRI in the other group. Both groups had cholesterol levels that significantly $(P \leq 0.01)$ exceeded that of the DRI. Consumption of vitamin D was significantly $(P \leq 0.01)$

Table 1 Average daily intake of nutrients (24-h recall) in relation to the dietary requirement intake (DRI) for foreign students who stayed for different periods of time at King Saud University using the $t$ test

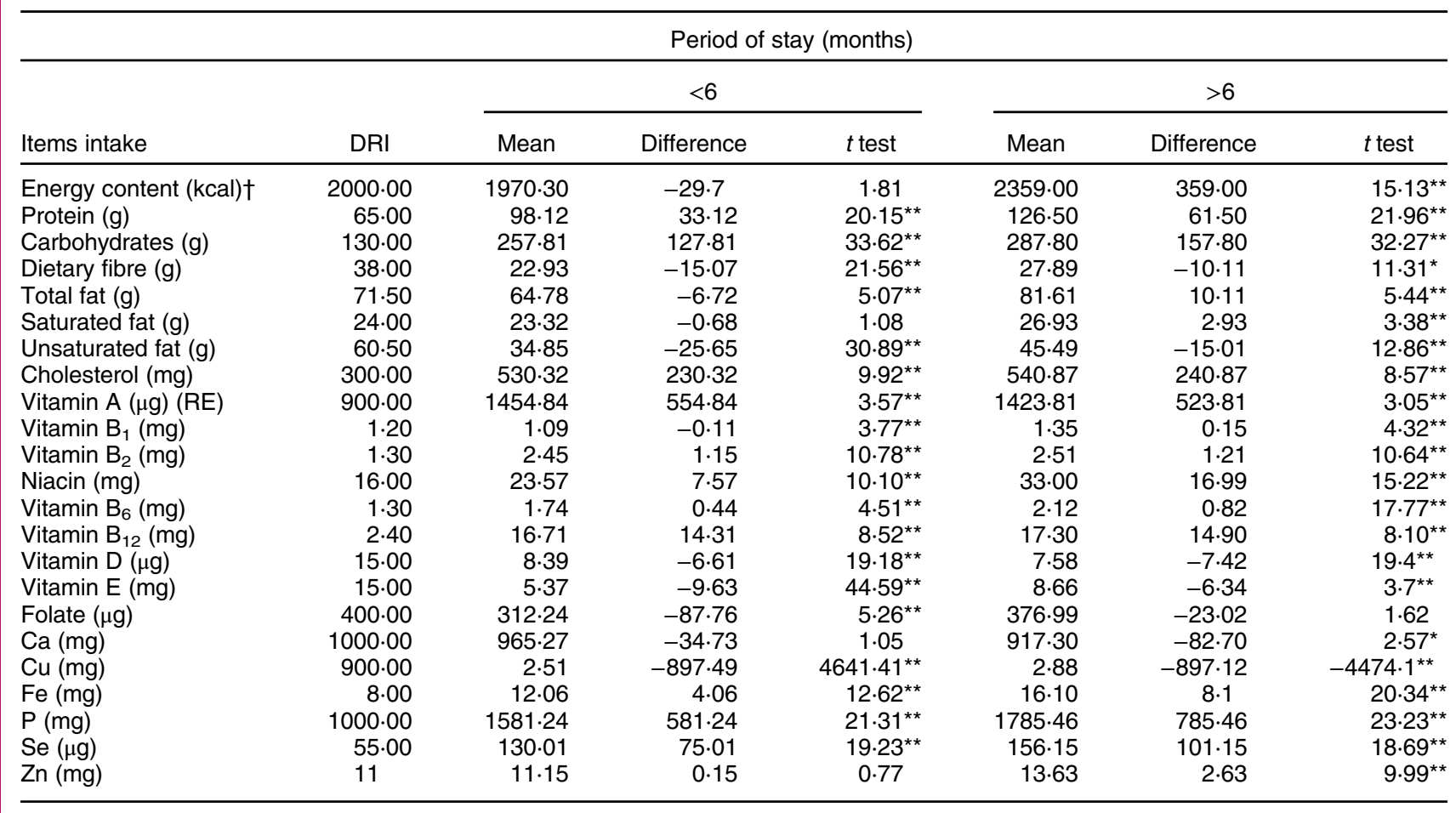

${ }^{\star \star} P \leq 0.01 ;{ }^{*} P \leq 0.05 ;$ Difference $=$ mean $-\mathrm{DRI}$

†To covert kcal to kJ multiply it by 4.184 . 
Table 2 BMl of the foreign students who stayed $<6$ months ( $n 200$ ) and those who stayed $>6$ months ( $n$ 200) according to the WHO's (1998) classifications

\begin{tabular}{|c|c|c|c|c|c|c|}
\hline \multirow[b]{3}{*}{ Interpretation } & \multicolumn{4}{|c|}{ Period of stay (months) } & & \\
\hline & \multicolumn{2}{|c|}{$<6$} & \multicolumn{2}{|c|}{$>6$} & \multicolumn{2}{|c|}{ Total } \\
\hline & Frequency & Percentage & Frequency & Percentage & Frequency & Percentage \\
\hline Underweight & 11 & $5 \cdot 5$ & 5 & 2.5 & 16 & 4 \\
\hline Normal & 135 & 67.5 & 26 & 13 & 161 & $40 \cdot 25$ \\
\hline Overweight & 49 & 24.5 & 123 & 61.5 & 172 & 43 \\
\hline Obesity I & 3 & 1.5 & 37 & 18.5 & 40 & 10 \\
\hline Obesity II & 1 & 0.5 & 9 & 4.5 & 10 & 2.5 \\
\hline Obesity III & 1 & 0.5 & 0 & 0 & 1 & 0.25 \\
\hline Total & 200 & 100 & 200 & 100 & 400 & 100 \\
\hline
\end{tabular}

$\chi^{2}(P=0.0004)$.

lower than that of the DRI in both groups. However, for those who stayed $>6$ months, their vitamin D consumption was accompanied by a significantly $(P \leq 0 \cdot 01)$ low level of $\mathrm{Ca}$. For Fe, Se, Zn, P and some vitamins, the results showed that the amount consumed by both groups was significantly $(P \leq 0.01)$ higher than that of the DRI.

The BMI of the students was measured and classified according to the $\mathrm{WHO}^{(17)}$ as shown in Table 2 . The results of the study showed that $5.5 \%$ of the students who stayed $<6$ months are underweight compared with $2.5 \%$ of those who stayed $>6$ months. About $67.5 \%$ of those who stayed $<6$ months have a normal BMI, while $24.5 \%$ of them were overweight. Additionally, 1, 0.5 and 0.5\% were obese and were classified into obesity levels I, II and III, respectively. Conversely, $13 \%$ of those who stayed $>6$ months had a normal BMI, while $61.5 \%$ of them were overweight. Further, 18 and $4.5 \%$ were obese and were classified into obesity levels I and II, respectively. The results reveal that the number of overweight and obese students who stayed $>6$ months exceeded that of the other group.

According to Lee et al. ${ }^{(9)}$, BMI as an indicator of a patient's obesity does not in all cases accurately reflect the degree of a patient's level of VF because the distribution of fat tissue varies between individuals. Therefore, in the current study, BF, VF and BMI were used as anthropometric proxies to determine the nutritional status of the students. Table 3 shows the levels of BF and VF of the foreign students who stayed $<6$ months ( $n$ 200) and those who stayed $>6$ months ( $n$ 200). According to the body composition analyser, $10.5 \%$ of the students who stayed $<6$ months have a decreased level of BF $v$. only $1 \%$ of those who stayed $>6$ months. Conversely, 66.5 and $97.5 \%$ of those who stayed $<6$ months had a normal level of $\mathrm{BF}$ and $\mathrm{VF}$, respectively. Comparatively, of those who stayed $>6$ months, 24.5 and $71 \%$ had a normal level of BF and $\mathrm{VF}$, respectively. About 19 and $1.5 \%$ of those who stayed $<6$ months had an increased level of BF and VF, respectively, $v .46 .5$ and $24.5 \%$ of those who stayed $>6$ months, respectively. Also, the results showed that 4 and $1 \%$ of the group who stayed $<6$ months had high levels of $\mathrm{BF}$ and VF, respectively, $v .28$ and $4.5 \%$ of those who stayed $>6$ months.

Table 4 shows some of the determinants factors that affect the nutritional status of the foreign students' according to the Spearman correlation coefficient and simple regression analysis between the students' anthropometric measurements as dependent variables and socio-economic characteristics of their families as independent variables.

Table 3 Body fat (BF) and visceral fat (VF) of the foreign students who stayed $<6$ months $(n 200)$ and those stayed $>6$ months $(n$ 200) according to the body composition analyser

\begin{tabular}{|c|c|c|c|c|c|c|c|c|}
\hline \multirow[b]{4}{*}{ Interpretation } & \multicolumn{4}{|c|}{$\mathrm{BF}$} & \multicolumn{4}{|c|}{ VF } \\
\hline & \multicolumn{8}{|c|}{ Period of stay (months) } \\
\hline & $<6$ & $>6$ & $<6$ & $>6$ & $<6$ & $>6$ & $<6$ & $>6$ \\
\hline & \multicolumn{2}{|c|}{ Frequency } & \multicolumn{2}{|c|}{ Percentage } & \multicolumn{2}{|c|}{ Frequency } & \multicolumn{2}{|c|}{ Percentage } \\
\hline Decreased & 21 & 2 & $10 \cdot 5$ & 1 & - & - & - & - \\
\hline Normal & 133 & 49 & 66.5 & 24.5 & 195 & 142 & 97.5 & 71 \\
\hline High & 38 & 93 & 19 & 46.5 & 3 & 49 & 1.5 & 24.5 \\
\hline Very high & 8 & 56 & 4 & 28 & 2 & 9 & 1 & 4.5 \\
\hline Total & 200 & 200 & 100 & 100 & 200 & 200 & 100 & 100 \\
\hline
\end{tabular}

BF: $\chi^{2}(P=0.012)$, VF: $\chi^{2}(P=0.000)$. 
BMI, BF and VF were used as indicators for the students' nutritional status. The age of the students who stayed $<6$ months was significantly and positively correlated with BMI $(P \leq 0.05)$ as well as BF and VF $(P \leq 0.01)$ with high effect observed on BF ( $\left.\beta^{* *}=0.05, r^{2}=0.07\right)$ compared with other proxies as shown by regression analysis. Moreover, for the same group, the mother's level of education was significantly $(P \leq 0.01)$ and negatively correlated with $\operatorname{VF}\left(\beta^{*}=-0.07, r^{2}=0.02\right)$ while marital status was significantly $(P \leq 0.05, P \leq 0.01)$ and positively correlated with $\mathrm{BF} \quad\left(\beta^{* *}=0.02, \quad r^{2}=0.03\right)$ and VF $\left(\beta^{* *}=0.05\right.$, $\left.r^{2}=0.06\right)$ with high effect on VF. Conversely, the age of the students who stayed $>6$ months was significantly $(P \leq 0.01)$ and positively correlated with VF $\left(\beta^{* * *}=0.08\right.$, $r^{2}=0.09$ ). Additionally, in this group, monthly income was significantly and positively correlated with $\mathrm{BF}$ $(P \leq 0.01), \mathrm{VF}(P \leq 0.05)$ and BMI $(P \leq 0.05)$ with high effect on BF ( $\left.\beta^{* *}=0.02, r^{2}=0.04\right)$ compared with other proxies as well as marital status with VF $(P \leq 0.01$, $\left.\beta^{* *}=0.03, r^{2}=0.05\right)$.

To investigate other determinant factors of the foreign students' nutritional status, Spearman correlation coefficients and simple regression analysis between the students' anthropometric measurements as dependent variables and daily food habits as independent variables were calculated (Table 5). For both groups, the number of meals per day was significantly $(P \leq 0.01)$ and positively correlated with the nutritional proxies. Regression analysis showed that the effect of the number of meals per day was low on BMI compared with $\mathrm{BF}$ and $\mathrm{VF}$ for students stayed $<6$ months, while for those stayed $>6$ months the effect on VF was high compared with BF and BMI. For foreign students who stayed $>6$ months, eating breakfast and having a special diet regime were significantly and negatively correlated with all nutritional status proxies. Moreover, eating breakfast had high effect on VF followed by BMI and BF while a special diet regime had high effect on BMI followed by BF and VF. In contrast, for those who stayed $<6$ months, having a special diet regime was positively correlated with $\mathrm{BF}(P \leq 0.05)$. The consumption of soft drinks by students who stayed $<6$ months was significantly and positively correlated with VF $(P \leq 0.05)$ and BMI $(P \leq 0.01)$ with high effect on VF.

\section{Discussion}

The present study was conducted to evaluate the nutritional status of foreign students currently staying in the Kingdom of Saudi Arabia at King Saud University. The results obtained for both groups showed that the students consume food that was high in carbohydrates, protein and some vitamins and minerals. According to the questionnaire data on daily food habits (data not shown), the results showed that most of the students in the current study had bad food habits like eating potato chips, sweets and other fast foods as their sources of carbohydrates. Students who 


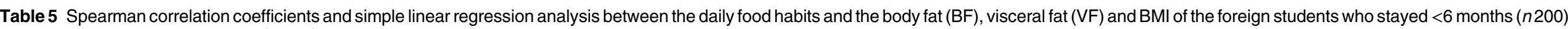
and those who stayed $>6$ months $(n 200)$

Period of stay (months)

\begin{tabular}{|c|c|c|c|c|c|c|c|c|c|c|c|c|}
\hline \multirow[b]{2}{*}{ Dependent variable/Independent variable } & & \\
\hline & BMI & $\left(\beta, r^{2}\right)$ & $\mathrm{BF}$ & $\left(\beta, r^{2}\right)$ & VF & $\left(\beta, r^{2}\right)$ & $\mathrm{BMI}$ & $\left(\beta, r^{2}\right)$ & $\mathrm{BF}$ & $\left(\beta, r^{2}\right)$ & VF & $\left(\beta, r^{2}\right)$ \\
\hline o. of meals/d & $0.144^{*}$ & $0.03^{*}, 0.02$ & $0.187^{\star *}$ & $0.02^{*}$ & $0.209^{\star \star}$ & $0.05^{\star \star}, 0 . c$ & $0.352^{\star \star}$ & $0.05^{\star \star}, 0.01$ & $0.304^{\star *}$ & $0.03^{\star \star}, 0.09$ & $0.400^{\star *}$ & $0.06^{*}$ \\
\hline at breakfast & -0.030 & $-0.02,0.007$ & -0.077 & $-0.01,0.01$ & -0.042 & $-0.02,0.007$ & $-0.218^{\star \star}$ & $-0.04^{\star \star}, 0.04$ & $-0 \cdot 158^{\star}$ & $-0.02^{*}, 0.02$ & $-0.213^{\star *}$ & $-0.04^{\star \star}, 0.05$ \\
\hline at at restaurant & -0.044 & $-0.001,0.001$ & -0.052 & $-0.005,0.001$ & -0.062 & $-0.01,0.001$ & 0.053 & $0.01,0.002$ & 0.051 & 0.002 & 0.074 & 0.0 \\
\hline cial food & 0.031 & $0.004,0.001$ & 0.021 & $0.002,0.001$ & 0.054 & $0.004,0.001$ & 0.036 & $0.001,0.001$ & 0.047 & $0.006,0.005$ & -0.045 & $0.008,0.003$ \\
\hline Special diet regime & 0.116 & $0.008,0.01$ & $0.156^{\star}$ & $0.005^{\star}, 0.02$ & 0.126 & $0.007,0.008$ & $-0.233^{\star \star}$ & $-0.01^{\star \star}, 0.08$ & $-0.259^{\star \star}$ & $-0.008^{\star \star}, 0.06$ & $-0.279^{\star *}$ & $-0.01^{\star \star}, 0.04$ \\
\hline nts or vitamins & 0.038 & $0.002,0.001$ & -0.015 & $-0.001,0.001$ & 0.020 & $0.002,0.001$ & -0.043 & $-0.001,0$ & -0.052 & $-0.001,0.001$ & -0.044 & $-0.001,0.001$ \\
\hline meals & 0.062 & $0.005,0.001$ & 0.055 & $0.007,0.002$ & 0.076 & $0.005,0.001$ & -0.013 & $-0.007,0.001$ & -0.015 & $-0.006,0.001$ & -0.065 & $-0.005,0.001$ \\
\hline Intake of soft drink & $0.182^{\star *}$ & $0.05^{\star}, 0.02$ & 0.134 & $0.02,0.01$ & $0 \cdot 168^{*}$ & $0.06^{*}, 0.03$ & 0.068 & $0.03,0.01$ & 0.121 & $0.02,0.01$ & 0.131 & $0.02,0.005$ \\
\hline to & -0.094 & $-0.02,0.004$ & -0.091 & $-0.01,0.005$ & -0.063 & $-0.01,0.002$ & & $0.007,0.001$ & & $0.02,0.008$ & & $0.02,0.004$ \\
\hline Consumption of potato chips & 0.014 & $0.02,0.004$ & -0.044 & $-0.003,0.001$ & -0.063 & $-0.005,0.001$ & 0.087 & $0.03,0.01$ & 0.074 & $0.02,0.02$ & 0.067 & $0.03,0.01$ \\
\hline
\end{tabular}

${ }^{*} P \leq 0.05,{ }^{*} P \leq 0.01$. Regression coefficients $(\beta)$, partial $r^{2}$ for independent variables of interest. 
stayed $>6$ months did not like to eat food prepared at home or at their boarding house which could lead to skipping meals and to have a low-quality diet, especially the low consumption of fruits and vegetables and a high intake of soft drinks ${ }^{(19)}$. Also, the students will develop a tendency to consume larger quantities of food when eating in group compared with eating alone or at home ${ }^{(20,21)}$. Moreover, the students who stayed $>6$ months consumed higher levels of saturated fat $v$. unsaturated fat compared with those who stayed $<6$ months. The results indicated that the students had an increased consumption of energy from carbohydrates and fats. The students mentioned that they had their meals either in a restaurant, at home or at their boarding houses. This may have affected the similarities between their diet patterns and the Saudi diet. Moreover, the participants were men which may be another factor that influenced their eating-out patterns ${ }^{(22)}$.

Additionally, the students' diet consisted of dishes that included rice or bread with meat and soups which contributed to their energy intake via carbohydrates. It has been reported that skipping meals, especially breakfast, does not result in accurate energy compensation at subsequent meals and accordingly daily energy intakes may decline ${ }^{(23)}$; this was observed in the students who stayed $<6$ months. The high intake of fruits and vegetables, as stated by the students, is the major factor that increased the level of some vitamins and minerals ${ }^{(24)}$. The results indicated that the students had developed a habit of eating fruit and vegetables as a result of their upbringing emphasises the importance of developing good dietary behaviour among children ${ }^{(25)}$.

Both groups had vitamin D deficiency which was accompanied by $\mathrm{Ca}$ deficiency. A healthy intake of vitamin $\mathrm{D}$ and exposure to sunlight are important as vitamin D metabolism occurs in the skin, under the effect of sunlight. A lack of vitamin D intake and exposure to sunlight are, therefore, the major factors leading to a decline in the body stores of vitamin $\mathrm{D}$ with age, leading to a high prevalence of hypo-vitaminosis D in the elderly. Also, a lower level of vitamin D can contribute to a lower bone mineral density ${ }^{(26)}$. For both groups, the increase in the intake of Fe is likely due to excessive consumption of food rich in proteins ${ }^{(27)}$.

In general, the ability of the international students to adapt to new cultures and the effect that various external factors have on their dietary behaviour cannot be underestimated. Adverse changes in dietary patterns such as reduced intake of fruits and vegetables, increased intake of sweets and fats and increased energy consumption have been reported ${ }^{(28)}$. Also, irregular eating habits, such as skipping meals (especially breakfast), and increasing snacking at irregular times have been documented ${ }^{(2)}$. International students, unlike many other immigrants, are often physically separated from their parents and other relatives for the first time and are faced with many new experiences on their own. Therefore, appropriate dietary recommendations and education would be beneficial ${ }^{(3)}$.
Malnutrition, in these students, was most likely caused by their lifestyle, adversely impacting their eating habits. Students, like many who stayed $>6$ months, who are overweight and obese are expected to spend a lot of time watching TV and playing video games ${ }^{(29)}$. This is expected to lead to a reduction of physical exercise and the encouragement of a sedentary lifestyle. This can adversely affect their eating habits and nutritional status; this has been observed in the high levels of BF, VF and BMI among students who stayed $>6$ months. The current study supports the hypothesis that meal patterns are greatly associated with obesity ${ }^{(30)}$. The results supported the study carried out by Al-Nozha et al. ${ }^{(31)}$ who concluded that the nutritional imbalance in Saudi Arabia is due to changes in food habits, illiteracy and ignorance, rather than a shortage of food supply or low income.

The results also supported the study of Park et al. ${ }^{(32)}$, who stated that the major cause of obesity and being overweight is an energy imbalance between energy content intake and energy content expended, which is caused by changes in dietary habits and levels of physical activity that accompanied by environmental and social changes associated with development and lack of supportive policies. Deliens et $a l .{ }^{(22)}$ reported that being male, living in a student residence, eating more frequently at the student restaurant, eating and drinking unhealthy, higher frequency of watching TV/DVD on weekdays, less weekly reading and studying and less hours of sleep on weekend days seem to explain the increase in BMI and fat\% partially. Furthermore, they showed that eating at a friend's place might imply less individual control over food-related choices. This could lead to rather unhealthy food choices, which may cause an increase in BMI as well. The results of the present work reflect the riskiness of the WHO's ${ }^{(17)}$ technical report series which concluded that the spread of obesity is increasing at an alarming rate, in both developing and developed countries.

The significant positive correlation between the students' age and the anthropometric proxies, especially on $\mathrm{BF}$ for those stayed $<6$ months and VF for those stayed $>6$ months as indicated by regression analysis, could be due to the fact that the students in Saudi Arabia are able to live a decent life. Consequently, the traditional factors correlating with nutritional status that are common in their home countries will affect them differently in Saudi Arabia, especially for those who have stayed for a longer time. Perissinotto et al. ${ }^{(33)}$ observed a positive correlation between age and the anthropometric proxies in elderly people. The significant negative correlation between the maternal level of education and the students' levels of $\mathrm{VF}$, especially for those who stayed $<6$ months, could be due to the fact that a less educated mother is not aware of proper dietary habits and the students are learning their eating habits from their mothers ${ }^{(34)}$. Also, we observed that monthly income and marital status were positively correlated with the anthropometric proxies and the level of 
the effect was varied between proxies. This could be because a higher income has allowed them to afford more decadent food, and consequently has lead them to have an unbalanced diet, eating fast food more frequently ${ }^{(34)}$.

The significant positive correlation between the number of meal per day and the anthropometric proxies with high effect on BF and VF revealed that as the number of meals per day increased, anthropometric proxies (BF, VF and BMI) increased; this can lead to being overweight or obese $^{(35)}$. For the students who stayed $>6$ months, skipping breakfast was the main determinant that lead to being overweight or obese by increasing the level of all proxies. This was also observed by Huang et al. ${ }^{(36)}$, who reported that breakfast skipping was correlated with an increased likelihood of obesity in Taiwanese adults, even after controlling for other variables that are frequently associated with obesity. In the present study, it was observed that following a special diet regime for the students who stayed $>6$ months negatively correlated with the anthropometric proxies. However, for those who stayed $<6$ months, this was negatively correlated with BF only. This is mainly because following a regime will provide the body only with the nutrients required, according to the students' daily activities. The consumption of soft drinks was positively correlated with the levels of VF and the BMI of those who stayed $>6$ months as it is high in sugars, providing more carbohydrates and, therefore, more energy ${ }^{(37)}$.

In the recent years, Saudi Arabia has witnessed an unprecedented development in all aspects of life, leading to more stable lifestyles and the consumption of a high-fat, low-fibre diet, which is believed to be linked to malnutrition-related health problems ${ }^{(38)}$. Thus, factors such as nutritional awareness and lifestyle are expected to correlate with nutritional status in contexts like the current study.

\section{Conclusion}

The current study showed that most of the students who stayed $>6$ months are suffered from overweight. This is assured by the fact that the students' average daily intake of energy, carbohydrates, protein, saturated fat and some vitamins and Fe ingested was significantly higher than that recommended by the DRI. Nutrition risk factors such as age, monthly income, marital status, number of meals per day and skipped meals were found to be significantly correlated with the students' health indicators. Thus, in addition to these, factors such as nutritional awareness and lifestyle are expected to be significantly correlated with nutritional status in the contexts of the current study. The study highlighted the need for more research on the consumption of out-of-home foods and its longitudinal effect on nutrition status and also the need to investigate other risk factors associated with the nutritional status of foreign students living in Saudi Arabia.

\section{Acknowledgements}

Financial support: The authors would like to extend their sincere appreciation to the 'Researchers Supporting Project' number (RSP-2019/84), King Saud University, Riyadh, Saudi Arabia. Conflict of interest: The authors declare that they have no conflict of interest. Authorship: M.A.M.: Contributing to the design of the work, data collection, analysis and interpretation of the work data. Drafting of the work and revising it critically. G.M.A.: Contributing to the design of the work, analysis and interpretation of the work data. Drafting of the work and revising it critically. Approval of the final version to be published, accountable for all aspects of the work and communication with the journal during the manuscript submission, peer review and publication process. E.E.B.: Contribute to the design of the work, analysis and interpretation of the work data. Drafting of the work and revising it critically. Approval of the final version to be published, accountable for all aspects of the work and communication with the journal during the manuscript submission, peer review and publication process. Ethics of human subject participation: The current study was conducted according to the guidelines laid down in the Declaration of Helsinki, and all procedures involving research study participants were approved by the research ethics committee of King Saud University (approval of research project No. E-19-3759). Written informed consent was obtained from all subjects as well as verbal consent.

\section{References}

1. Lee J, Gao RR \& Kim JH (2015) Acculturation and changes in dietary behavior and anthropometric measures among Chinese international students in South Korea. Nutr Res Pract 9, 304-312.

2. Blundell J, Gumaste D, Handley R et al. (2003) Behaviour and cognitive functions: a psychobiological view. Scand $J$ Nutr 47, 85-89.

3. McDonald JT \& Kennedy S (2005) Is migration to Canada associated with unhealthy weight gain? Overweight and obesity among Canada's immigrants. Soc Sci Med 61, 2469-2481.

4. Caballero B (2007) The global epidemic of obesity: an overview. Epidemiol Rev 29, 1-5.

5. De Henauw S, Gottrand F, De Bourdeaudhuij I et al. (2007) Nutritional status and lifestyles of adolescents from a public health perspective. The HELENA project-healthy lifestyle in Europe by nutrition in adolescence. J Pub Heal 15, 187-197.

6. Majeed F (2015) Association of BMI with diet and physical activity of female medical students at the University of Dammam, Kingdom of Saudi Arabia. J Taibah Univ Med Sci 10, 188-196.

7. Correia MITD (2018) Nutrition screening vs nutrition assessment: what's the difference? Nutr Clin Prac 33, 62-72.

8. Carpenter CL, Yan E, Chen S et al. (2013) Body fat and bodymass index among a multiethnic sample of college-age men and women. J Obes 2013, 790654. doi: 10.1155/2013/ 790654 .

9. Lee WJ, Wang W, Chen TC et al. (2003) Clinical significance of central obesity in laparoscopic bariatric surgery. Obes Surg 13, 921-925. 
10. Seki Y, Ohue M, Sekimoto M et al. (2007) Evaluation of the technical difficulty performing laparoscopic resection of a rectosigmoid carcinoma: visceral fat reflects technical difficulty more accurately than body mass index. Surg Endosc 21, 929-934.

11. Bandyopadhyay A (2007) Anthropometry and body composition in soccer and volleyball players in West Bengal, India. J Phys Anthrop 26, 501-505.

12. Imamura Y, Uto H, Oketani M et al. (2008) Association between changes in body composition and the increasing prevalence of fatty liver in Japanese men. Hepatol Res $\mathbf{3 8}$, 1083-1086.

13. Akay AF, Gedik A, Tutus A et al. (2007) Body mass index, body fat percentage, and the effect of body fat mass on SWL success. Inter Urol Nephrol 39, 727-730.

14. Abalkhail B \& Shawky S (2002) Comparison between body mass index, triceps skin fold thickness and mid-arm muscle circumference in Saudi adolescents. Ann Saudi Med 22 324-328.

15. Aldalbahi M \& Walker G (2015) Attitudes and policy implications of urban growth boundary and traffic congestion reduction in Riyadh, Saudi Arabia. In International Conference Data Mining 1-2, pp. 56-64.

16. Lwanga SK, Lemeshow S \& World Health Organization (1991) Sample size determination in health studies: a practical manual.

17. World Health Organization (1998) Obesity: preventing and managing the global epidemic. Report on a WHO Consultation on Obesity, Geneva.

18. Kyle UG, Bosaeus I, De Lorenzo AD et al. (2004) Bioelectrical impedance analysis - part i: review of principles and methods. Clin Nutr 23, 1226-1243.

19. Rodrigues PR, Luiz M, Monteiro RR et al. (2017) Adolescents' unhealthy eating habits are associated with meal skipping. Nutrition 42, 114-120.

20. Larson N \& Story M (2009) A review of environmental influences on food choices. Ann Behav Med 38, 56-73.

21. Cluskey M \& Grobe D (2009) College weight gain and behavior transitions. Male and female differences. JAmer Diet Assoc 109, 325-329.

22. Deliens T, Clarys P, Van Hecke L et al. (2013) Changes in weight and body composition during the first semester at university. A prospective explanatory study. Appetite 65, 111-116.

23. Levitsky DA \& Pacanowski CR (2013) Effect of skipping breakfast on subsequent energy intake. Physiol Behav 119, 9-16.

24. Slavin JL \& Lloyd B (2012) Health benefits of fruits and vegetables. Adv Nutr 3, 506-516.
25. Hartman H, Wadsworth DP, Penny S et al. (2013) Psychosocial determinants of fruit and vegetable consumption among students in a New Zealand University. Results of focus group interviews. Appetite 65, 35-42.

26. Arya V, Bhambri R, Godbole MM et al. (2004) Vitamin D status and its relationship with bone mineral density in healthy Asian Indians. Osteop Intern 15, 56-61.

27. Geissler C \& Singh M (2011) Iron, meat and health. Nutrients 3, 283-316.

28. Drewnowski A, Darmon N \& Briend A (2004) Replacing fats and sweets with vegetables and fruits - a question of cost. Amer J Public Health, 94, 1555-1559.

29. Mo-suwan L, Nontarak J, Aekplakorn W et al. (2014) Computer game use and television viewing increased risk for overweight among low activity girls. Inter J Pedia 2014, 364702. doi: 10.1155/2014/364702.

30. Berg C, Lappas G, Wolk A et al. (2009) Eating patterns and portion size associated with obesity in a Swedish population. Appetite 52, 21-26.

31. Al-Nozha MM, Al-Mazrou YY, Al-Maatouq MA et al. (2005) Obesity in Saudi Arabia. Saudi Med J 26, 824-829.

32. Park HS, Yun YS, Park JY et al. (2003) Obesity, abdominal obesity, and clustering of cardio-vascular risk factors in South Korea. Asia Pac J Clin Nutr 12, 411-418.

33. Perissinotto E, Pisent C, Sergi G et al. (2002) Anthropometric measurements in the elderly: age and gender differences. BrJ Nutr 87, 177-186.

34. Khayri HO, Muneer SE, Ahmed SB et al. (2016) Assessment of the nutritional status of Sudanese primary school pupils in Riyadh city, Kingdom of Saudi Arabia. J Immig Mino Health 18, 28-33.

35. Estima CD, da Costa CP, Sichieri RS et al. (2009) Meal consumption patterns and anthropometric measurements in adolescents from a low socioeconomic neighborhood in the metropolitan area of Rio De Janeiro, Brazil. Appetite 52, 735-739.

36. Huang CJ, Hu HT, Fan YC et al. (2010) Associations of breakfast skipping with obesity and health-related quality of life: evidence from a national survey in Taiwan. Inter $J$ Obes 34, 720-725.

37. Vartanian LR, Schwartz MB \& Brownell KD (2007) Effects of soft drink consumption on nutrition and health: a systematic review and meta-analysis. Am J Public Health 97, 667-675.

38. Boutelle K, Birnbaum A, Lytle L et al. (2003) Associations between perceived family meal environment and parent intake of fruit, vegetables and fat. J Nutr Educ Behav 35, 24-29. 